\title{
Environmental enrichment reverses $A \beta$ pathology during pregnancy in a mouse model of Alzheimer's disease
}

\author{
Stephanie Ziegler-Waldkirch ${ }^{1,2}$, Karin Marksteiner ${ }^{1,2}$, Johannes Stoll ${ }^{1,2}$, Paolo d’Errico ${ }^{1,2}$, Marina Friesen ${ }^{1,3,4}$, \\ Denise Eiler ${ }^{1,2}$, Lea Neudel ${ }^{1,2}$, Verena Sturn ${ }^{1,2}$, Isabel Opper ${ }^{1,2}$, Moumita Datta ${ }^{2,4}$, Marco Prinz $z^{2,4,5}$ \\ and Melanie Meyer-Luehmann ${ }^{1,2,6^{*}}$ (D)
}

\begin{abstract}
Several studies suggest that women have a higher risk to develop Alzheimer's disease (AD) than men. In particular, the number of pregnancies was shown to be a risk factor for $A D$ and women with several pregnancies on average had an earlier onset of the disease, thus making childbearing a risk factor. However, the impact of being pregnant on $A \beta$ plaque pathology and adult neurogenesis still remains elusive. Postmortem analysis revealed that pregnant 5xFAD transgenic mice had significantly more A $\beta$ plaques in the hippocampus from G10 onwards and that the number of Ki67 and DCX positive cells dramatically decreased during the postpartum period. Furthermore, 5 months old 5xFAD transgenic mice that also nursed their offsprings for 4 weeks had a similar A $\beta$ plaque load than merely pregnant mice, indicating that pregnancy alone is sufficient to elevate $A \beta$ plaque levels. Interestingly, housing in an enriched environment reduced the $A \beta$ plaque load and vivified neurogenesis. Our results suggest that pregnancy alters $A \beta$ plaque deposition in 5XFAD transgenic mice and diminishes the generation of newborn neurons. We conclude that pregnancy alone is sufficient to induce this phenotype that can be reversed upon environmental enrichment.
\end{abstract}

Keywords: Alzheimer's disease, Pregnancy, Amyloid- $\beta$ plaques, Adult neurogenesis, Estrogens, Progesterone, Environmental enrichment

\section{Introduction}

Alzheimer's disease (AD) is the most common type of dementia that is characterized by a decline in memory. The majority of $\mathrm{AD}$ cases are sporadic [9] and the greatest non-genetic risk factors for the development of $\mathrm{AD}$ are age and gender. The incidence of the disease is higher in women than in men, which was previously attributed to the higher longevity of women versus men. Several epidemiological studies suggest however that there may be other factors contributing to the disease beyond longevity. In particular, women with multiple pregnancies had an earlier onset of $\mathrm{AD}[6,7,31]$ and nulliparous women had significantly less age related

\footnotetext{
* Correspondence: melanie.meyer-luehmann@uniklinik-freiburg.de ${ }^{1}$ Department of Neurology, Medical Center - University of Freiburg, Freiburg, Germany

${ }^{2}$ Faculty of Medicine, University of Freiburg, Freiburg, Germany

Full list of author information is available at the end of the article
}

cognitive decline [25], while the number of children had no effect on the risk of developing $\mathrm{AD}$ [31]. Together, these studies indicate reproductive experience being a risk factor for $\mathrm{AD}$, but the underlying mechanism for this higher risk of AD in women is still largely unknown.

In agreement with those aforementioned studies, gender-dependent elevated $A \beta$ plaque formation has been observed in several APP transgenic mouse models. Female APP transgenic mice that exhibit massive cerebral amyloid deposition while aging developed more $A \beta$ pathology with an earlier onset than their male siblings $[1,5,14,35,39]$. Additionally, fertility experience of those female APP transgenic mice altered A $\beta$ plaque pathology, resulting in even higher $A \beta$ plaque numbers and larger plaque sizes when compared to non-breeders [8]. Furthermore, these neuropathological changes were associated with spatial memory impairment and the down-regulation of synaptophysin levels in APP transgenic breeders. 
Adult neurogenesis is a lifelong process in the healthy adult mammalian brain, where functional neurons are generated from adult neural stem cells and adult neural precursor cells. Emerging evidence has indicated that altered neurogenesis in the adult hippocampus represents a critical event in the course of $\mathrm{AD}$ and that cognitive deficits, learning difficulties and memory loss in $\mathrm{AD}$ patients may be due to impaired adult neurogenesis $[10,15,20,21]$. Intriguingly, environmental enrichment and voluntary exercise were shown to increase the number of newborn granule cells in the dentate gyrus $[18,19,26,37,38]$ and to reduce $A \beta$ plaque formation in APP transgenic mice [16, 22]. Despite the immense interest in the therapeutic potential of environmental enrichment during pregnancy, the impact on the mother however still remains elusive since most studies focus on the offspring $[3,13]$.

Therefore, we aimed to investigate neuropathological changes such as $A \beta$ plaque load and adult neurogenesis during the course of pregnancy at different gestation days. Our results demonstrate that pregnant $5 \times \mathrm{xFAD}$ transgenic mice had a significantly higher $A \beta$ plaque load in different brain regions such as hippocampus, cortex and the olfactory bulb. Interestingly, 5 month old 5xFAD transgenic mice that also nursed their offspring for 4 weeks had an $A \beta$ plaque load similar to merely pregnant mice, indicating that pregnancy alone is sufficient to elevate $\mathrm{A} \beta$ plaque levels. Furthermore, neurogenesis was dramatically decreased in both groups during the postpartum period compared to $5 \mathrm{xFAD}$ mice. Exposure of pregnant $5 x F A D$ mice to an enriched environment reduced $A \beta$ deposits and stimulated the generation of newborn neurons, thus underlining the beneficial effects of exercise and enrichment during pregnancy.

\section{Material and methods \\ Animals}

We used heterozygous $5 \mathrm{xFAD}$ transgenic mice co-expressing $\begin{array}{lllll}\text { human APP } & \text { K670N/M671L } & (\mathrm{Sw})+1716 \mathrm{~V} & \text { (Fl) }+\operatorname{V7171}(\mathrm{Lo}) & \text { and }\end{array}$ $\mathrm{PS}^{\mathrm{M} 146 \mathrm{~L}+\mathrm{L} 286 \mathrm{~V}}$ under the control of the neuron-specific Thy-1 promoter [27]. We backcrossed 5xFAD mice with $\mathrm{C} 57 \mathrm{BL} / 6$ mice to generate heterozygous $5 \mathrm{xFAD}$ mice and non-transgenic littermates on the same genetic background. Only female mice were used in the present study. Animals were group-housed under specific pathogen-free conditions. Mice were kept under a 12-h light, 12-h dark cycle with food and water ad libitum. All animal experiments were carried out in accordance with the policies of the state of Baden-Württemberg under license number X14/02A and X17/01A.

Female mice were mated at the age of 12 weeks. The matings were initiated in the afternoon and the mice were separated after a positive plug check on the following morning. The day of vaginal plaque formation was estimated as gestation day 1 (G1). In order to analyze female mice at different stages of pregnancy, they were sacrificed on G5, G10 and G18. Non- pregnant $5 \times$ FAD female mice of the same age and from the same litters were used as control groups. To study the lactation period, female mice were mated at the age of 12 weeks and were divided into three groups. One group delivered and lactated the offspring for 4 weeks. One group was separated from their litter directly after the delivery and the third group was not pregnant and did not lactate. All mice were analyzed at postpartum day 20 (P20). To study how multiple pregnancies might affect A $\beta$ pathology, 10 months old female mice were analyzed. Two groups of female mice, nulliparous and multiparous (4 times pregnant and lactating) were used.

\section{Environmental enrichment}

5xFAD female mice were mated at the age of 12 weeks. One group of mice was housed in standard cages and another group of mice in an enriched environment until G18 or P20. The environmental enrichment consisted of larger cages $(40 \times 60 \mathrm{~cm})$ that contained 1 running wheel, tunnel systems, small plastic houses and extra nesting material. The animals had free access to the running wheel. Mice were housed in groups of 5 . All mice were sacrificed at the end of the experiment at G18 or P20.

\section{Histology}

Mice were deeply anesthetized with a mixture of ketamine (300 mg per $\mathrm{kg}$ ) and xylazine (20 mg per $\mathrm{kg}$ ) before they were transcardially perfused with $20 \mathrm{ml}$ of ice-cold PBS followed by $20 \mathrm{ml}$ of ice-cold $4 \%$ paraformaldehyde in PBS. Brains were isolated and postfixed in $4 \%$ PFA for $24 \mathrm{~h}$, followed by incubation in $30 \%$ sucrose (in PBS, pH 7.5) for a further $48 \mathrm{~h}$. Frozen brains were cut into $25 \mu \mathrm{m}$ thick coronal sections on a sliding microtome (SM2000R, Leica Biosystems, Wetzlar, Germany) and collected in PBS. Immunohistochemistry was performed on free floating sections using the following antibodies diluted in PBS containing 5\% normal goat serum and $0.5 \%$ Triton X-100: anti-A $\beta 3552$ (rabbit polyclonal antibody specific for $A \beta 1-40$ [40] (kindly provided by E. Kremmer, Ludwig Maximilians University, Munich, Germany); diluted 1:3000), anti-doublecortin (rabbit, DCX; 1:5000, abcam, ab18723), anti-Ki67 (rabbit, 1:500, abcam, ab15580). Appropriate secondary antibodies conjugated to Alexa 488 or 555 (1:1500) were used. Dense-core plaques were stained with Thiazinred (Sigma, T3272). Staining was done according to standard protocols. In brief, sections were washed 3 times in PBS and incubated in Thiazinred ( $2 \mu \mathrm{M}$ solution in PBS) for $5 \mathrm{~min}$ at RT followed by $3 \times 5 \mathrm{~min}$ washes with PBS. 


\section{Assessment of $A \beta$ and cell analysis}

Fluorescence images of brain slices were taken using a Zeiss fluorescent microscope (Axio Imager M2M). For analysis every tenth brain section of one hemisphere was used. The total $A \beta$ load was determined by counting the $A \beta$-positive stained plaques using the imaging software ImageJ (National Institutes of Health freeware). Ten sections per animal were analyzed for the hippocampus and cortex and 8 sections per animal for the olfactory bulb, in total 4-6 animals per group were investigated. $A \beta$ plaque load is presented in $\%$ and normalized to the non-pregnant control group (set to 100\%).

The cell number was quantified by counting the number of positively labeled cells in the animal's whole dentate gyrus. Four to six animals per group and 10 sections per animal were analyzed. Cell counting was done in the dentate gyrus and its area was measured with the ImageJ software. The area of the gyrus was defined according to the mouse brain atlas [29]. Cell numbers are presented as the quantity of positively labeled cells per $\mathrm{mm}^{2}$. All analyses were conducted in a blinded manner.

\section{Western blot analysis}

Total protein from hippocampus was extracted in RIPA buffer $(50 \mathrm{mM}$ HEPES pH 7.5, $150 \mathrm{mM} \mathrm{NaCl}, 1 \mathrm{mM}$ EDTA, 10\% Glycerin, 1\% Triton X-100, $10 \mathrm{mM} \mathrm{Na}_{4} \mathrm{O}_{7} \mathrm{P}_{2}$, Protease Inhibitor). Protein concentration was determined by Pierce BCA Protein Assay Kit (ThermoFisher). Samples were separated by $4-12 \%$ NuPAGE Bis-tris mini gels using NuPAGE LDS sample buffer, NuPAGE sample reducing agent and NuPAGE MES SDS running buffer (Invitrogen). Proteins were transferred on PVDF membranes (Biorad) and visualized using Clarity Western ECL Substrate (Biorad). Antibodies against APP and CTFs (rabbit polyclonal antibody against the APP C-terminus, 6687, 1:1000) [34], anti-A $\beta$ (mouse, 1:3000, Covance, 6E10), anti-insulin degrading enzyme (anti-IDE) (rabbit, 1:5000, abcam, ab109538), anti-neprilysin 1:2500 (rabbit, 1:2500, abcam, ab79423) and anti- $\beta$-actin-HRP (mouse, 1:5000, abcam, ab20272) were used.

\section{ELISA}

For the measurement of estrogen and progesterone levels, blood samples were taken from the ventricle before the perfusion of the mice at G5, G10 or G18. Blood was centrifuged immediately for $10 \mathrm{~min}$ at $1800 \mathrm{~g}$. The supernatant was frozen at $-20{ }^{\circ} \mathrm{C}$ until analysis. Serum samples were prepared and analyzed by Mouse/Rat Estradiol ELISA kit (Calbiotech, catalog no. ES180S-100) or Progesterone ELISA Kit (Enzo, Enzo Life Science) according to the manufacturer's protocols. Samples were measured in duplicates and the ELISA was conducted in two to three independent experiments.
For the quantification of $\mathrm{A} \beta 40$ and 42 species in the soluble and insoluble hippocampal extracts, hippocampal tissue was homogenized $(10 \% w / v)$ in PBS + protease inhibitor and sequentially extracted with PBS (soluble fraction), PBS + 0.1\% TritonX100 (membrane bound fraction) and finally with $8 \mathrm{M}$ guanidine hydrochloride solution. Protein concentration in each fraction was measured with Bradford reagent (Roth) and ELISA was performed using Human A $\beta 42$ ultrasensitive ELISA kit (Life Technologies, catalog no. KHB3544) and Human A 340 ELISA kit (Life Technologies, catalog no. KHB3481), according to the manufacturer's protocol.

\section{Statistical analysis}

GraphPad Prism 6 (GraphPad Software, Inc) was used for statistical analysis. All data sets were tested for normality with the D'Agostino-Pearson omnibus K2 normality test with a significance level set to $P=0.05$ before carrying out the appropriate parametric or nonparametric statistical comparison test. The Mann-Whitney test or Kruskal-Wallis test followed by Dunn's posthoc test were applied. Reported values are means \pm S.D. Significance level $\alpha$ was set to 0.05 . ${ }^{*} P<0.05$; ${ }^{* * *} P<0.01$; ${ }^{* * * *} P<0.001$.

\section{Results \\ Pregnancy-related alteration of $A \beta$ plaque pathology in female 5xFAD mice}

To investigate if pregnancy induces pathological alterations, we first determined the $A \beta$ plaque load in $5 x F A D$ transgenic female mice at different stages of pregnancy/ gestation days and compared them to their age-machted non-pregnant littermates. 5xFAD transgenic mice were mated at the age of 12 weeks and were analyzed on gestation day 5, 10 and 18 (G5, 10, 18) (Fig. 1a). At G5, there was no difference between the $A \beta$ plaque load of pregnant mice and non-pregnant littermates (Fig. $1 b$ and $c$ ). While the total number of $A \beta$ plaques was already increased in pregnant mice at G10, particularly in the subiculum, the number of thiazin red positive compact $A \beta$ plaques did not differ (Fig. 1d and e). At G18, both, the number of total and of compact $A \beta$ plaques significantly increased in pregnant $5 x F A D$ mice when compared to controls (non-breeders) at the same age (Fig. $1 \mathrm{f}$ and g). In accordance with this higher plaque load in pregnant $5 x F A D$ mice, we found that soluble and insoluble levels of $A \beta 40$ and $A \beta 42$ were increased but did not reach statistical significance in pregnant mice at G18 (Fig. 1h and i). To further determine if multiple pregnancies augment this effect, we next analyzed 40 weeks old female $5 x F A D$ mice that had been pregnant 4 times (multiparous) and compared them with nulliparous mice of the same age (Fig. 2a). Although many plaques were detected in the hippocampi of nulliparous and multiparous 5xFAD transgenic mice 
a
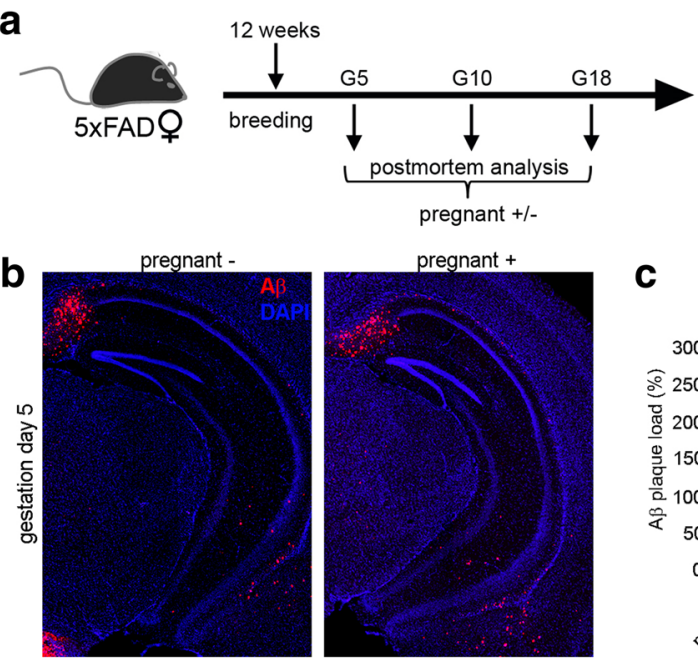

C
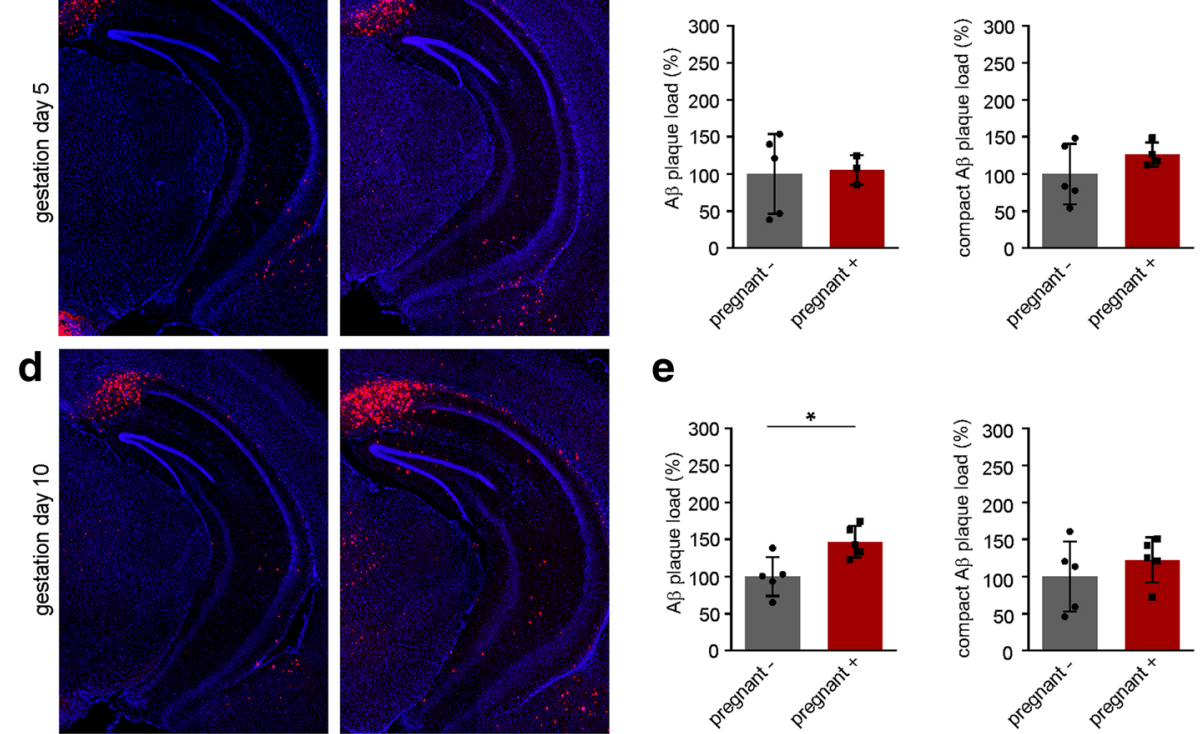

e
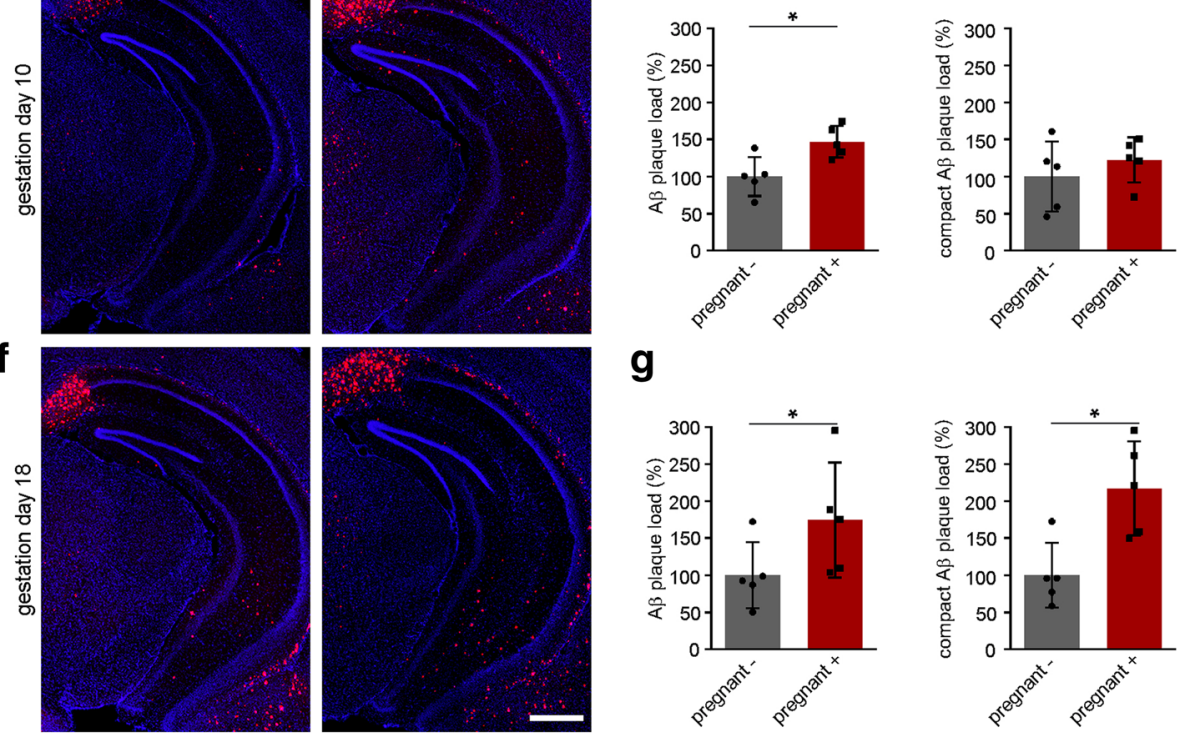

\section{g}
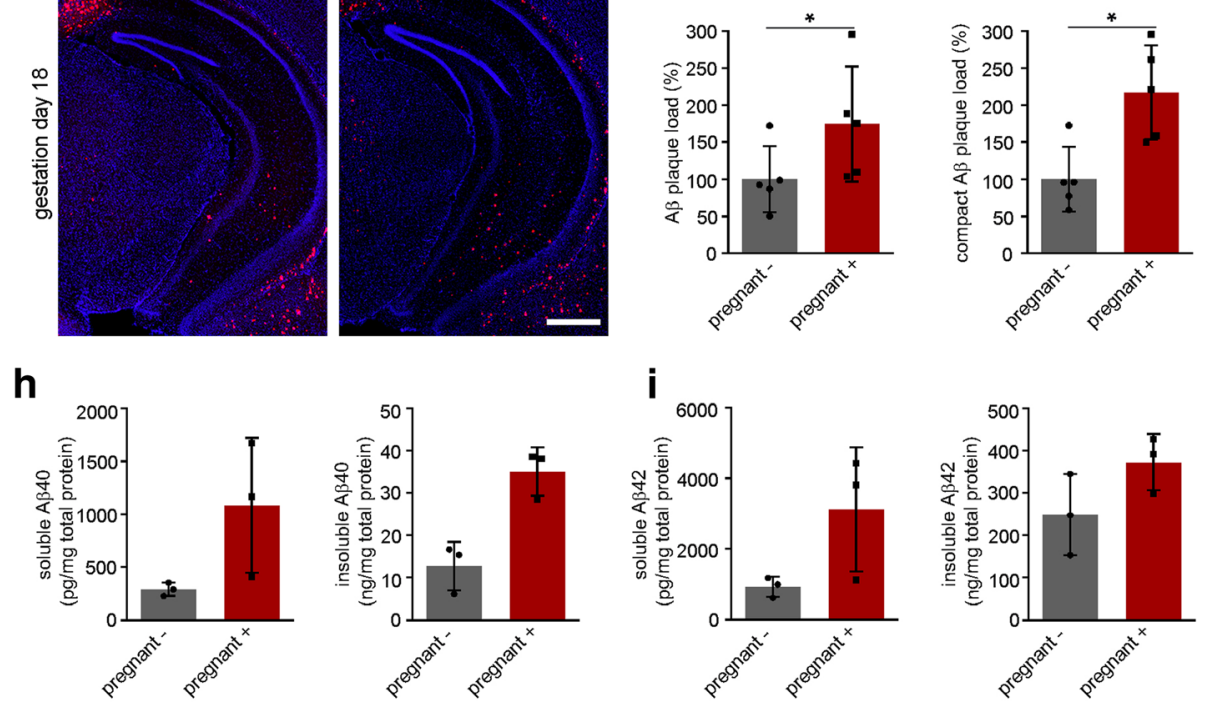

Fig. 1 (See legend on next page.) 
(See figure on previous page.)

Fig. 1 A $\beta$ plaque load increases during pregnancy from gestation day 5 to gestation day 18 in $5 x F A D$ female mice. a Schematic overview of the experimental setup. Twelve weeks old 5xFAD female mice were breed and either sacrificed at gestation day 5 (G5), G10 or G18. b Fluorescence microscopy of A $\beta$ (red) and DAPI (blue). Shown are representative images of hippocampi from female 5xFAD mice not pregnant or pregnant at G5. c Quantification of A $\beta$ plaque load (left) and compact A $\beta$ plaque load (right) of not pregnant and pregnant 5xFAD mice at G5 showed no differences between the groups. $\mathbf{d}$ Fluorescence microscopy of $A \beta$ (red) and DAPI (blue). Shown are representative images of hippocampi from female 5xFAD mice not pregnant or pregnant at G10. e A $\beta$ plaque load (left) is significantly increased in pregnant 5xFAD female mice compared to not pregnant mice at G10. Mann-Whitney test, ${ }^{*} P=0.03$. f Fluorescence microscopy of A $\beta$ (red) and DAPI (blue). Shown are representative images of hippocampi from female 5xFAD mice not pregnant or pregnant at G18. $\mathbf{g}$ The number of $A \beta$ plaques exhibited significant increase in pregnant 5xFAD mice compared to not pregnant 5xFAD mice at G18. Mann-Whitney test, ${ }^{*} P=0.03$. $\mathbf{h}$ Sandwich immunoassay for $A \beta 40$ soluble and insoluble fractions of hippocampal brain extracts from non-pregnant and pregnant female 5xFAD mice at G18 $(n=3)$. i Sandwich immunoassay for A $\beta 42$ soluble and insoluble fractions of hippocampal brain extracts from non-pregnant and pregnant female 5xFAD mice at G18 $(n=3)$. Data are presented as mean \pm S.D. Each symbol represents data from one mouse, with four to five mice per group. Scale bar represents $500 \mu \mathrm{m} . \mathrm{G}=$ gestation day

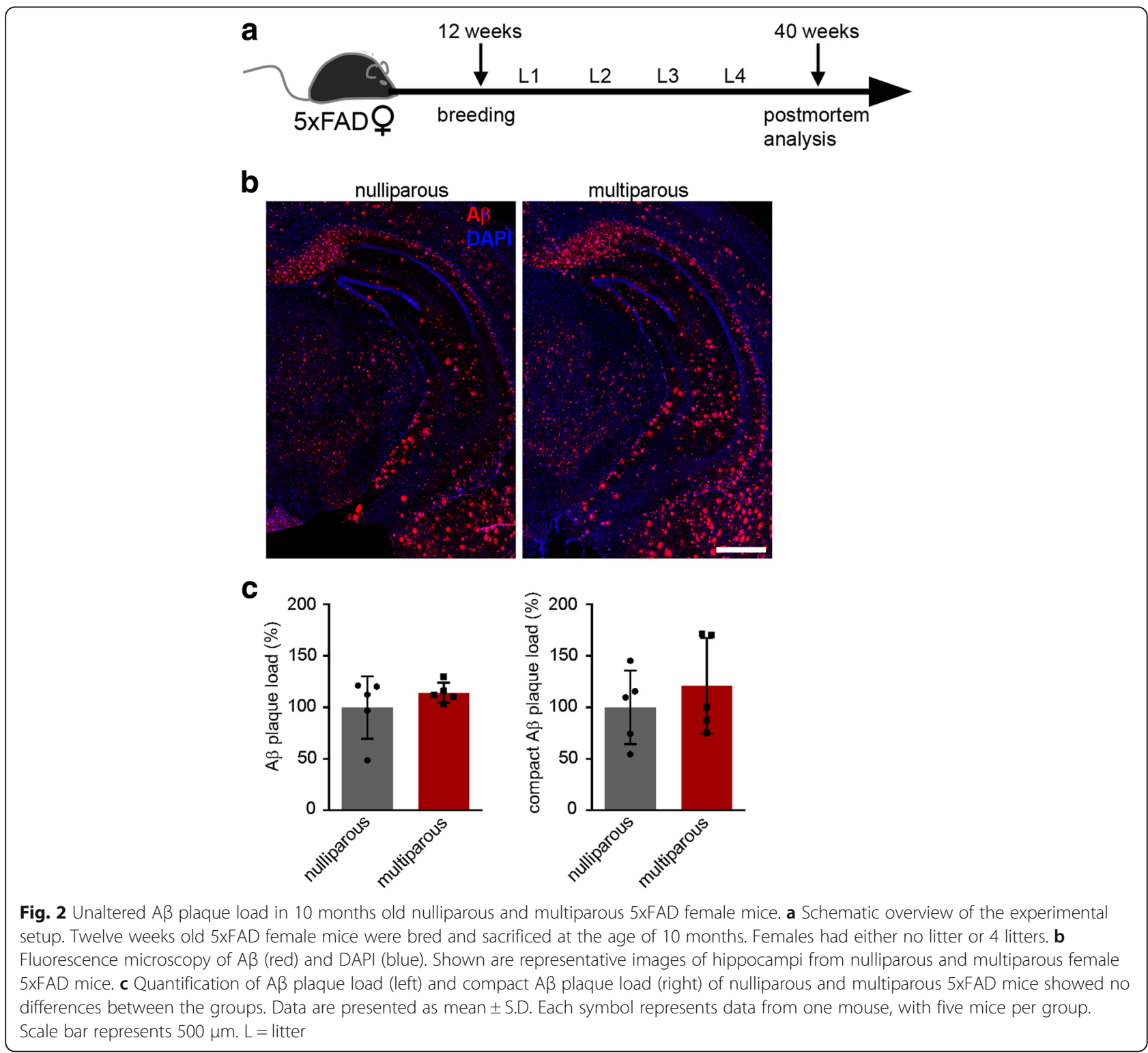


(Fig. 2b), A $\beta$ plaque load did not differ between both groups (Fig. 2c) most likely due to an $A \beta$ overload.

In order to elucidate whether higher $A \beta$ plaque load and $A \beta$ levels in pregnant mice (G18) (Fig. 3a) result from either increased $A \beta$ production or decreased $A \beta$ degradation, we performed Western blot analyses. While full length APP levels were similar, there was a strong increase in monomeric A $\beta$ and APP C-terminal fragments (in particular CTF- $\beta$ ) in pregnant mice, indicating that pregnancy affects the processing of APP and augments $A \beta$ production (Fig. $3 b$ ).

Next, we collected blood samples to determine serum estrogen and progesterone levels of non-pregnant and pregnant 5xFAD female mice at G0, G5, G10 and G18. ELISA measurements revealed significant increases in estrogen levels both in pregnant WT and 5xFAD female mice from G5 onwards (Fig. 3c). Serum progesterone levels were enhanced at G10 in pregnant WT and 5xFAD mice. At G18, pregnant WT mice exhibited significantly higher progesterone levels when compared to non-pregnant littermates. Moreover, pregnant 5xFAD mice showed dramatically increased progesterone levels that even exceeded those of pregnant WT mice at G18 (Fig. 3d).

To rule out any effect of pregnancy on the clearance or degradation of $A \beta$, we determined the protein levels of the enzymes involved in $A \beta$ degradation, neprilysin and IDE, which revealed mixed results. While neprilysin levels were not affected by pregnancy, we found increased IDE levels as measured by Western blotting in the hippocampus of pregnant mice (Fig. 3e), probably due to higher progesterone levels (Fig. 3d) that were shown to significantly increase IDE in vivo in rats [17].

Together, these data suggest that pregnancy modulates $A \beta$ plaque load by increasing the generation of $A \beta$.

\section{Pregnancy and lactation impair $A \beta$ plaque load in several brain regions of $5 x F A D$ mice}

In search of a more detailed approach towards the relationship between pregnancy, motherhood and $A \beta$ deposition, we tested the hypothesis that lactation itself might have an effect on $A \beta$ pathology. Therefore, we mated 12 weeks old 5 xFAD mice and subdivided

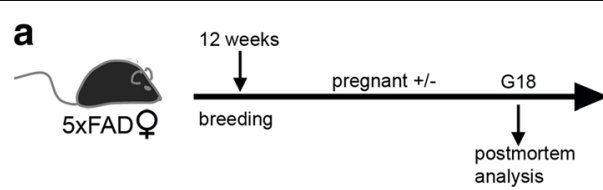

b

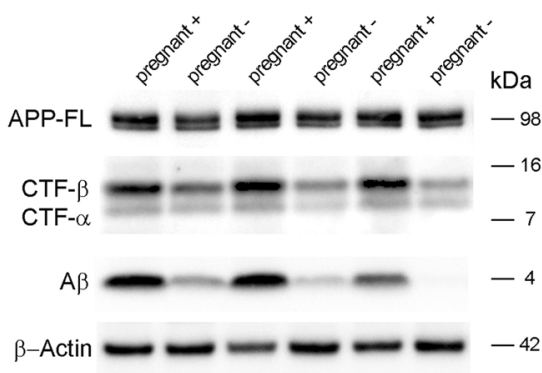

e
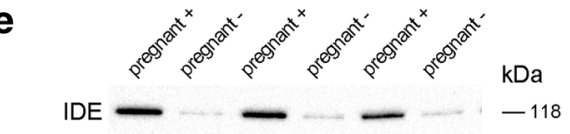

Neprilysin ---100

$\beta$-Actin $=--\infty=--\infty$
C

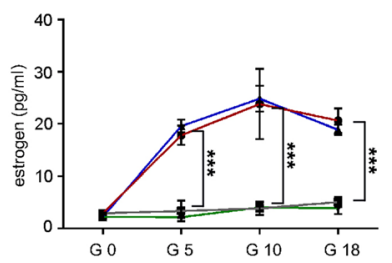

d

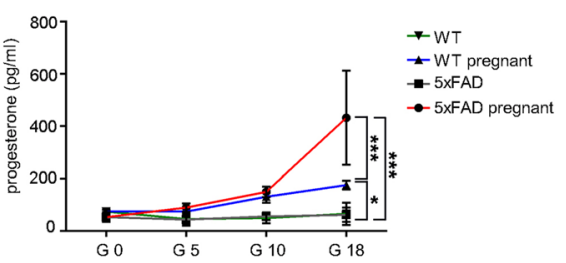

Fig. 3 APP processing is altered in pregnant 5xFAD mice during pregnancy. a Schematic overview of the experimental setup. Twelve weeks old 5XFAD female mice were bred and sacrificed at gestation day 18. $\mathbf{b}$ Immunoblot analysis of hippocampal brain homogenates from pregnant and non-pregnant 5xFAD mice at G18. Immunoblots were probed with antibodies that recognize human full length APP, CTF- $\beta$ and CTFa (6687) and $A \beta$ (6E10). $\beta$-Actin was used as loading control. Pregnant $5 x F A D$ mice showed higher levels of CTF- $\beta$ and A $\beta$ while APP levels were unaltered. $\mathbf{c}$ Serum estrogen levels of $5 \times F A D$ and WT female mice were measured by ELISA at G0, G5, G10 and G18. Estrogen levels increased during pregnancy in $5 \times F A D$ and WT mice $\left({ }^{* *} P<0.0001,{ }^{* * *} P<0.0001\right.$; $\left.{ }^{* *} P<0.0001\right)$. d Serum progesterone levels of female $5 \times F A D$ and WT mice were measured by ELISA at G0, G5, G10 and G18. Progesterone levels increased significantly during pregnancy in $5 \times F A D$ and $W T$ mice $(* P=0.03$;

${ }^{* * *} P<0.0001$; $\left.{ }^{* *} P<0.0001\right)$. e Levels of IDE and neprilysin were detected by western blotting in pregnant and non-pregnant $5 \times F A D$ mice. $\beta$ Actin was used as loading control. Data are presented as mean \pm S.D. Three mice per group were used.

$\mathrm{G}=$ gestation day, IDE = insulin-degrading-enzyme 
the females after birth into the following 3 groups: a) non-pregnant, b) pregnant but non-lactating and c) pregnant and lactating. All mice were analyzed 4 weeks after delivery at postpartum day 20 (P20) (Fig. 4a). A $\beta$ immunohistochemistry revealed a significantly higher $\mathrm{A} \beta$ plaque load in pregnant and lactating female mice compared to non-pregnant mice. Female mice that delivered but were separated from their litter directly after birth had enhanced hippocampal $A \beta$ plaque numbers compared to non-pregnant ones but did not differ from the lactating group (Fig. $4 \mathrm{~b}$ and c). To confirm these observations in other brain regions, $A \beta$ plaques were analyzed in the cortex and olfactory bulb of the same $5 x F A D$ mice by immunohistochemistry (Fig. $4 \mathrm{~d}$ and $\mathrm{f}$ ). In accordance with the results obtained in the hippocampus, the total and compact $A \beta$ plaque load was significantly enhanced in pregnant and lactating female $5 \mathrm{xFAD}$ mice at P20 (Fig. 4e), albeit not reaching significance for the total $\mathrm{A} \beta$ plaque load in the olfactory bulb (Fig. 4g). In summary, we conclude from these results that pregnancy alone is sufficient to induce this phenotype as lactation has no influence on this pathology.

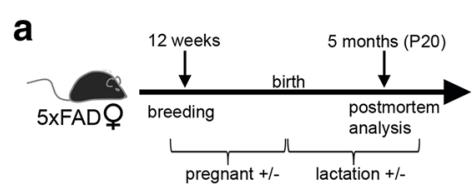

b
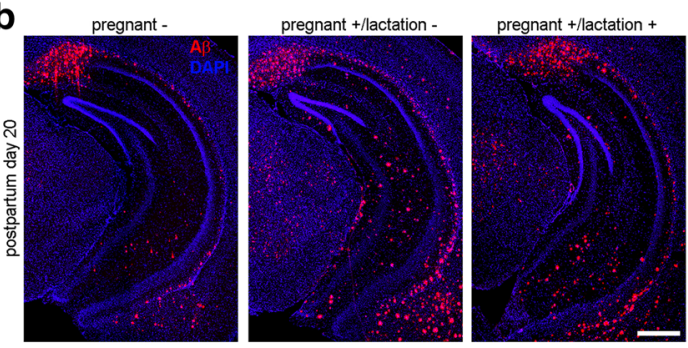

C

d
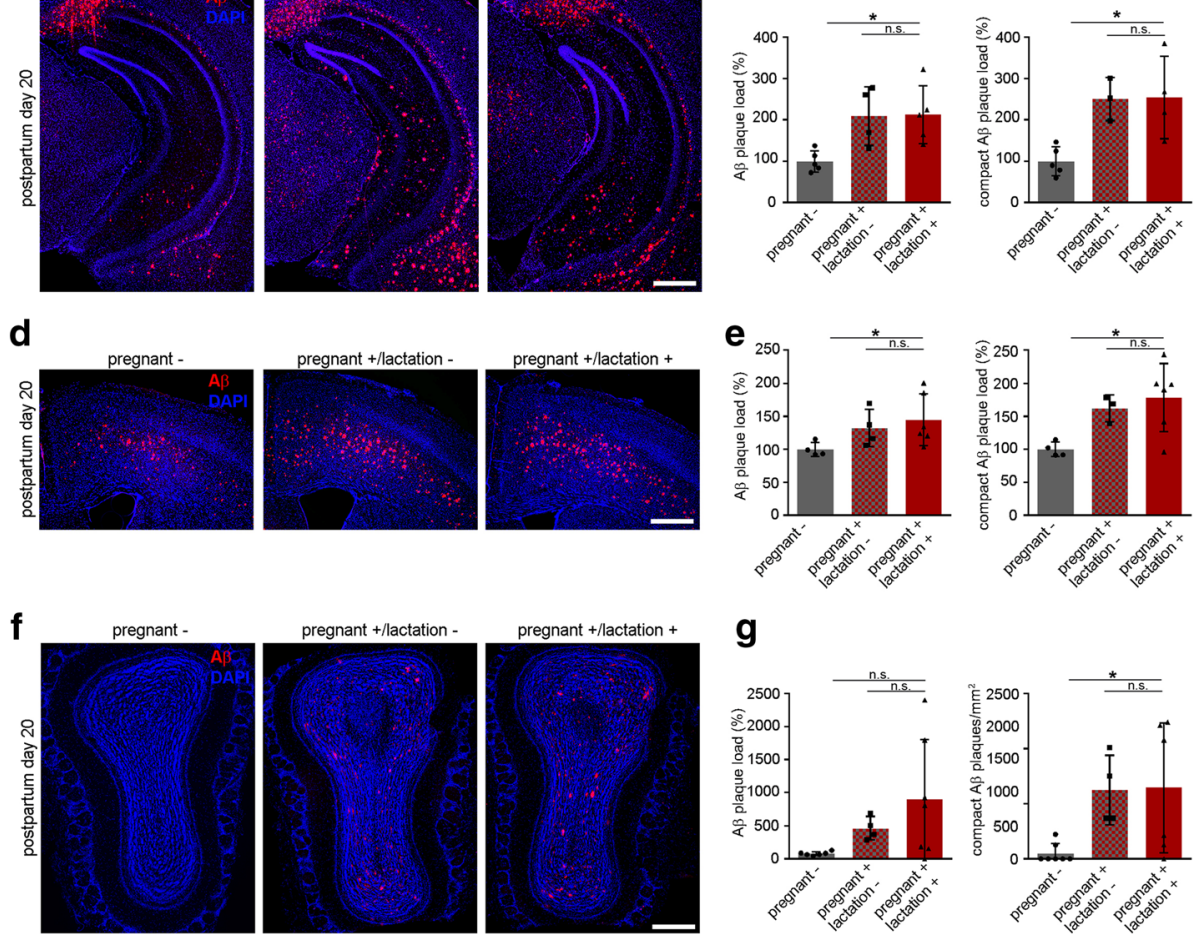

Fig. 4 Pregnancy and not lactation increases A $\beta$ plaque pathology in different brain regions of 5xFAD female mice. a Schematic overview of the experimental setup. Twelve weeks old 5xFAD female mice were mated and sacrificed at the age of 5 months (postpartum day 20 (P20)) after the pregnancy and lactation period. One group of mice was separated from the litter directly after the delivery and analyzed 4 weeks later at P20. b Fluorescence microscopy of A $($ red) and DAPI (blue). Shown are representative images of hippocampi from female 5xFAD mice either non-pregnant, pregnant but not lactating or pregnant and lactating at P20. c Quantification of A $\beta$ plaque load exhibited significant increases in pregnant and lactating 5xFAD mice. Kruskal-Wallis test followed by Dunn's multiple comparison test, ${ }^{*} P=0.03,{ }^{*} P=0.03$. d Fluorescence microscopy of A $\beta$ (red) and DAPI (blue). Shown are representative images of the cortex from female 5xFAD mice either non pregnant, pregnant but not lactating or pregnant and lactating at P20. e Quantification of A $\beta$ plaque load in the cortex exhibited significant increases in pregnant and lactating 5xFAD mice compared to nulliparous 5xFAD female mice. Kruskal-Wallis test followed by Dunn's multiple comparison test, ${ }^{*} p=0.04$, ${ }^{*} p=0.03$. $\mathbf{f}$ Fluorescence microscopy of AB (red) and DAPI (blue). Shown are representative images of the olfactory bulb from female $5 \times F A D$ mice either non-pregnant, pregnant but not lactating or pregnant and lactating at P20. $\mathbf{g}$ Analysis of the number of compact $A \beta$ plaques in the olfactory bulb exhibited significant increases in pregnant and lactating 5xFAD mice compared to nulliparous 5xFAD female mice. Kruskal-Wallis test followed by Dunn's multiple comparison test, $P=0.056,{ }^{*} P=0.02$. Data are presented as mean \pm S.D. Each symbol represents data from one mouse, with four to seven mice per group. Scale bar represents $500 \mu \mathrm{m}$. P = postpartum day 
Adult hippocampal neurogenesis and cell proliferation are decreased during pregnancy and lactation period in 5xFAD mice

We determined proliferation and neurogenesis in 5xFAD transgenic and WT mice at P20 and compared them to their non-pregnant littermates to study the effect of pregnancy, lactation and $A \beta$ plaque pathology on cells. While the number of doublecortin (DCX) positive cells dramatically declined during pregnancy in WT and 5xFAD mice, the number of DCX positive neuroblasts and immature neurons did not differ between pregnant/non-lactating and pregnant/lactating 5xFAD females at P20 (Fig. 5a and b), corroborating the aforementioned effect of pregnancy alone. Likewise, the number of Ki67 positive proliferating cells in pregnant WT and 5xFAD mice was significantly decreased (Fig. 5c and d).
Exposure to environmental enrichment and voluntary running during pregnancy circumvents $A \beta$ plaque pathology and vivifies neurogenesis

Inspired by studies that report beneficial effects on the A $\beta$ plaque burden in APP transgenic mice [22] upon exposure to an environmental enrichment (EE) and voluntary running, we exposed pregnant $5 x F A D$ mice to EE during 18 days, based on a published protocol [3], and compared them with pregnant 5xFAD mice housed in standard cages (SH) (Fig. 6a). First, we focused on the question if exposure of the mice to an enriched environment influences their estrogen and progesterone levels. Indeed, progesterone levels of pregnant $5 x F A D$ mice housed in EE dropped significantly to levels that were comparable to WT pregnant mice housed in $\mathrm{SH}$, while estrogen levels remained unaffected (Fig. 6b). Intriguingly, hippocampal and cortical $\mathrm{A} \beta$ plaque pathology
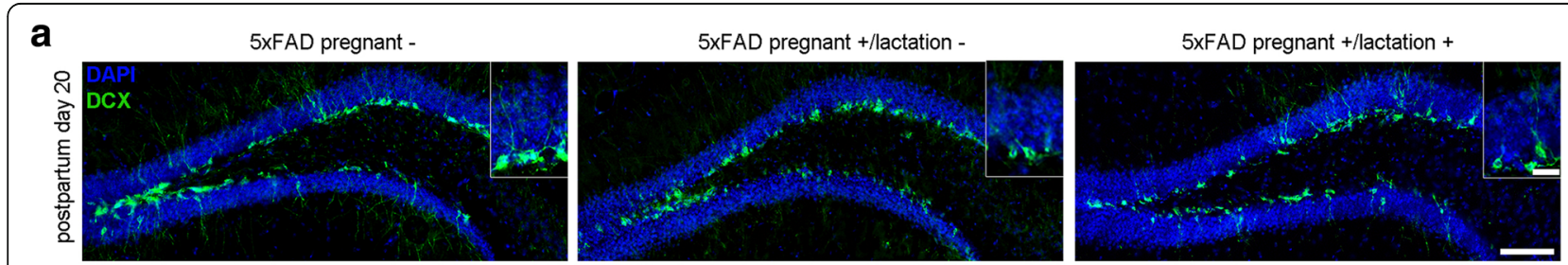

b
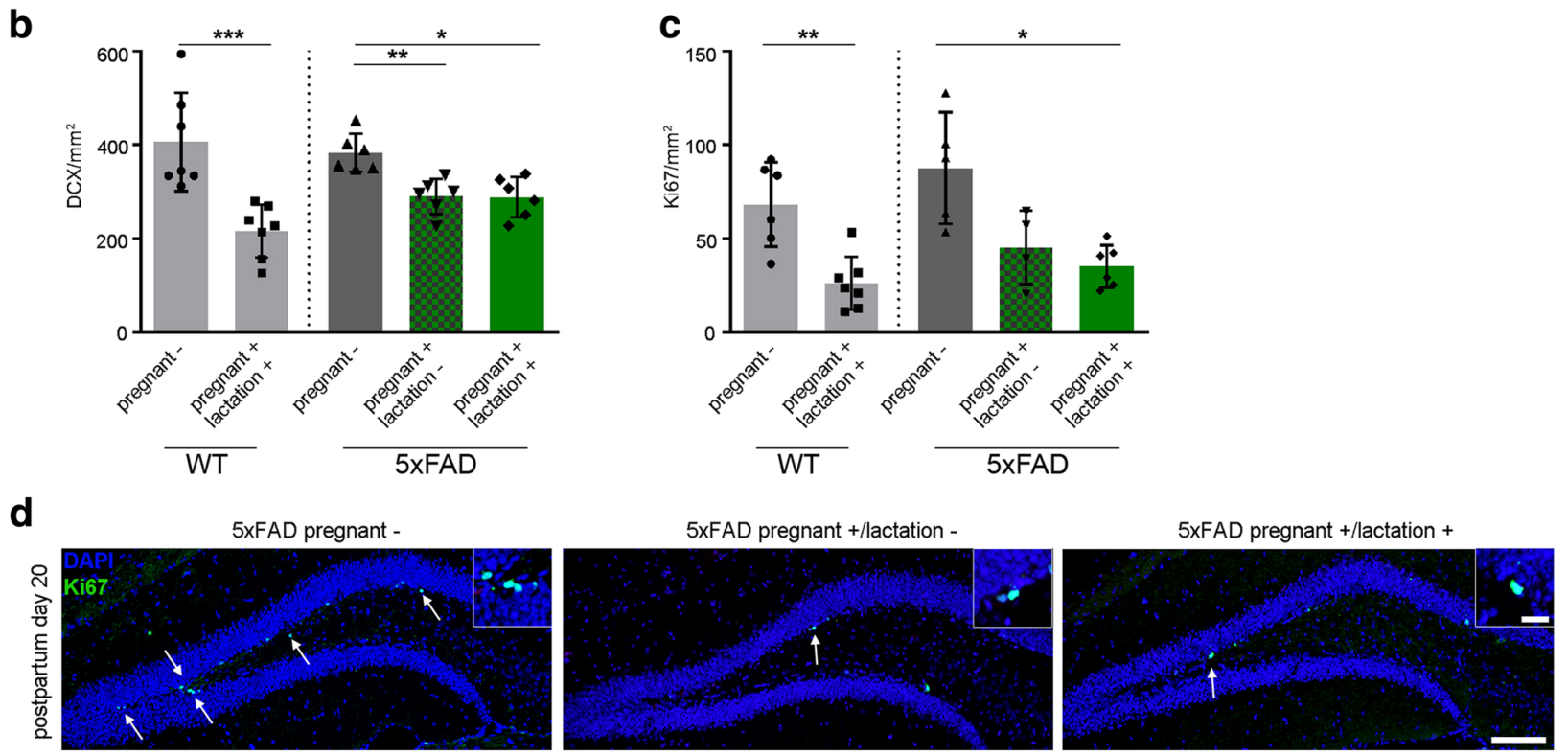

Fig. 5 Decreased adult neurogenesis in pregnant and lactating WT and 5xFAD female mice at P20. a Fluorescence microscopy of DCX (green) and DAPI (blue). Shown are representative images of the dentate gyrus from 5xFAD female mice sacrificed at the postpartum day 20 (P20). Inserts show higher magnifications. b Quantification of DCX positive cells displayed significant reductions in pregnant and lactating WT and 5XFAD female mice at P20. Mann-Whitney test, ${ }^{*} P=0.0015$, Kruskal-Wallis test followed by Dunn's multiple comparison test, ${ }^{*} P=0.0089,{ }^{*} P=0.012$. c Quantification of Ki67 positive cells exhibited significant reductions in pregnant and lactating WT and 5XFAD female mice at P20. Mann-Whitney test, ${ }^{*} P=0.0047$, Kruskal-Wallis test followed by Dunn's multiple comparison test, ${ }^{*} P=0.02$. d Fluorescence microscopy of Ki67 (green) and DAPI (blue). Shown are representative images of the dentate gyrus from 5xFAD female mice sacrificed at P20. White arrows indicate the presence of Ki67 positive cells. Inserts show higher magnifications. Scale bar represents $100 \mu \mathrm{m}$ in the overview and $20 \mu \mathrm{m}$ in the inserts. Data are presented as mean \pm S.D. Each symbol represents data from one mouse, with five to seven mice per group. $P=$ postpartum day, $D C X=$ doublecortin 

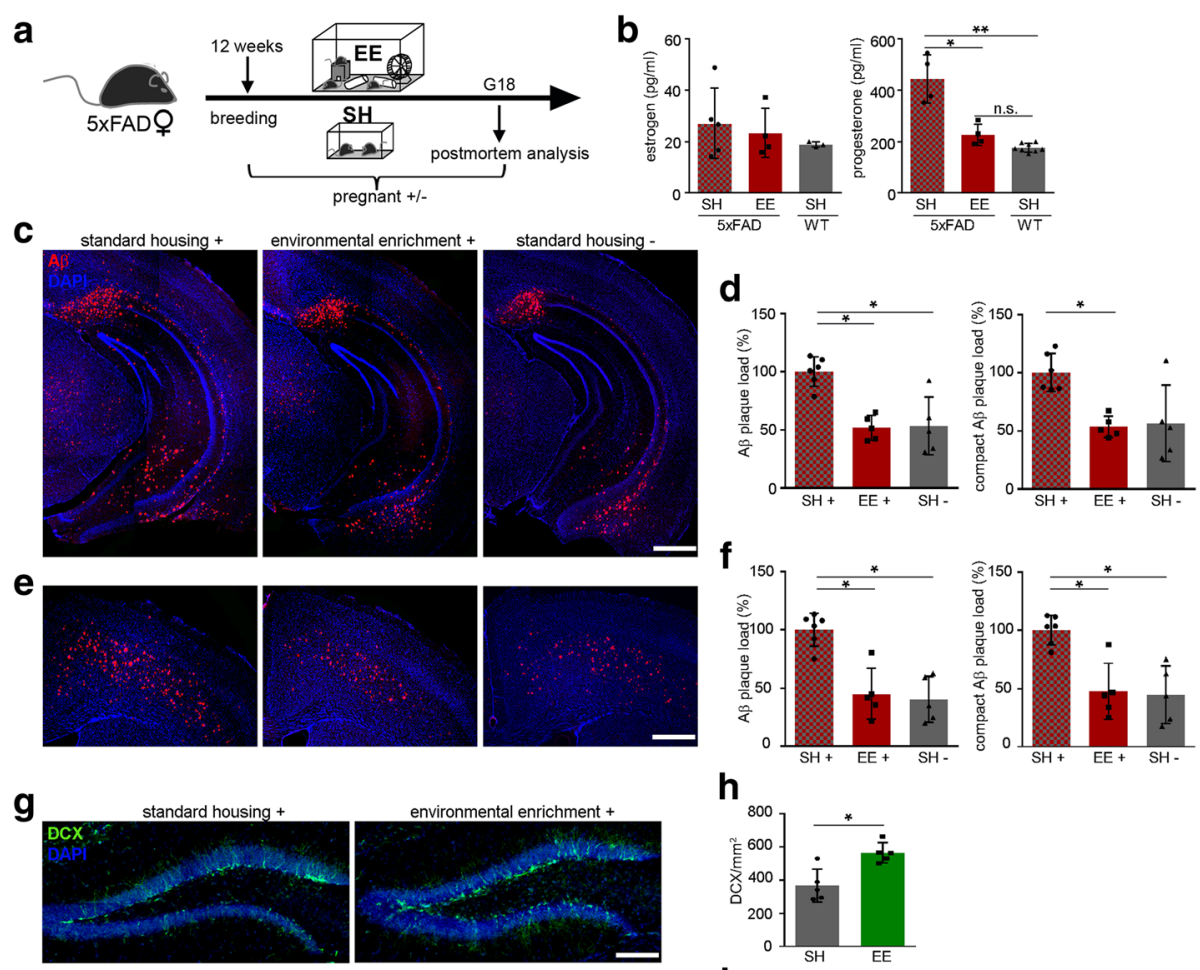

h
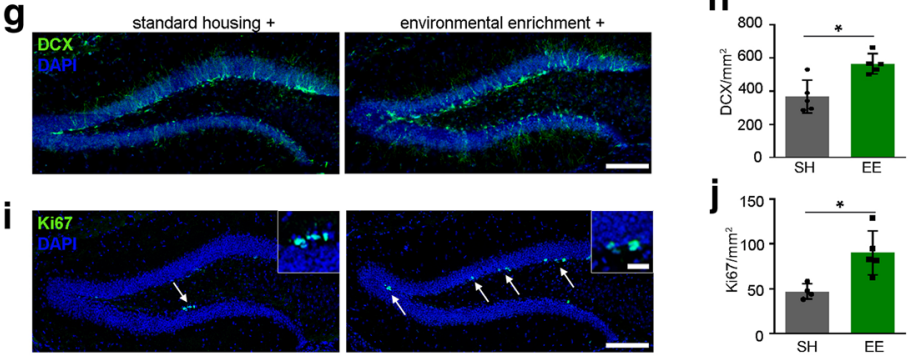

Fig. 6 Environmental enrichment prevents increase in A $\beta$ plaque pathology during pregnancy in 5xFAD mice. a Schematic overview of the experimental setup. Twelve weeks old 5xFAD female mice were mated and either housed in standard housing (SH) or in environmental enrichment (EE) until they were sacrificed at gestation day 18 (G18). b Serum estrogen and progesterone levels of pregnant 5xFAD and WT female mice exposed to EE or SH were measured by ELISA at G18. Estrogen levels did not differ between EE and SH housed female mice. Progesterone levels decreased in 5xFAD mice housed in EE to the level of standard housed pregnant WT mice. Kruskal-Wallis test followed by Dunn's multiple comparison test, ${ }^{*} P=0.03,{ }^{*} P=0.0025$. c Fluorescence microscopy of A $(\mathrm{red})$ and DAPI (blue). Shown are representative images of hippocampi from pregnant female 5xFAD mice housed in SH or EE and non-pregnant housed in SH. d Quantification of A $\beta$ plaque load (left) and compact A $\beta$ plaque load (right) of pregnant 5xFAD mice housed in SH or EE displayed significant decreases in the number of A $\beta$ plaques after housing in EE. Kruskal-Wallis test followed by Dunn's multiple comparison test, ${ }^{*} P=0.027,{ }^{*} P=0.0178,{ }^{*} P=0.0364$. e Fluorescence microscopy of AB (red) and DAPI (blue). Shown are representative images of the cortex from pregnant female $5 \times F A D$ mice housed in SH or EE and non-pregnant mice housed in SH. $\mathbf{f}$ Quantification of A $\beta$ plaque load in the cortex of pregnant 5xFAD mice at G18 exhibited significant decreases in mice housed in EE. Kruskal-Wallis test followed by Dunn's multiple comparison test, ${ }^{*} P=0.040,{ }^{*} P=0.012,{ }^{*} P=0.033,{ }^{*} P=0.014$. g Fluorescence microscopy of DCX (green) and DAPI (blue). Shown are representative images of the dentate gyrus from pregnant 5xFAD female mice housed in SH or EE sacrificed at G18. $\mathbf{h}$ Quantification of DCX positive cells in pregnant 5xFAD mice showed significant increases in mice housed in EE. Mann-Whitney test, ${ }^{*} P=0.03$. i Fluorescence microscopy of Ki67 (green) and DAPI (blue). Shown are representative images of the dentate gyrus from pregnant female 5xFAD mice housed in SH or EE. $\mathbf{j}$ Analysis of Ki67 positive cells in pregnant 5xFAD mice revealed significant increases in mice housed in EE. Mann-Whitney test, ${ }^{*} P=0.02$. Inserts show higher magnifications. White arrows indicate Ki67 positive cells. Scale bar represents $500 \mu \mathrm{m}$ in (c and $\mathbf{e}$ ) and $100 \mu \mathrm{m}$ in ( $\mathrm{g}$ and i) and $20 \mu \mathrm{m}$ in the insert. Data are presented as mean \pm S.D. Each symbol represents data from one mouse, with four to six mice per group. $\mathrm{SH}=$ standard housing, $\mathrm{EE}=$ environmental enrichment, $\mathrm{DCX}=$ doublecortin, $\mathrm{G}=$ gestation day

was significantly decreased in pregnant 5xFAD mice housed in EE compared to pregnant mice housed in $\mathrm{SH}$ and even reached an $\mathrm{A} \beta$ plaque load similar to the non-pregnant control group housed in SH (Fig. 6c - f).

Since earlier studies reported beneficial effects on adult hippocampal neurogenesis upon exposure to an environmental enrichment (EE) [18, 19] and voluntary running $[37,38]$, we focused on the question whether EE could be beneficial for pregnant 5xFAD mice as well, by stimulating cell proliferation and adult neurogenesis. Consistent with the literature [18], pregnant 5xFAD mice housed under SH conditions had significantly less DCX labeled cells compared to mice housed in EE (Fig. 6g and h). Moreover, by quantifying Ki67 positive cells, it was clearly evident that pregnant mice housed in EE had significantly more proliferation compared to their counterparts in SH (Fig. 6i and j). 
Given the positive effects of EE during pregnancy, we then tested whether the increased $A \beta$ plaque burden during pregnancy and lactation could be reduced or even halted by exposure to an EE. Therefore, 5xFAD mice were mated at the age of 12 weeks and exposed directly to EE from G1 onwards until the end of the weaning period (P20) (Fig. 7a). Indeed, quantitative analysis of $A \beta$ plaque numbers displayed a reduced hippocampal plaque burden in lactating mice housed in EE compared to mice housed in $\mathrm{SH}$ that even were comparable to those of the non-pregnant control group housed in SH (Fig. 7b and c).
Similar results were obtained by examining $A \beta$ plaques in the cortex (Fig. $7 \mathrm{~d}$ and e), suggesting an overall beneficial effect of $E E$ on $A \beta$ plaque pathology.

Finally, we studied the influence of EE on cell proliferation and adult neurogenesis in pregnant and lactating $5 x F A D$ mice. Consistent with our previous findings, housing $5 \mathrm{xFAD}$ female mice during pregnancy and the lactation period (P20) in EE resulted in a significantly enhanced number of DCX and Ki67 labeled cells compared to mice housed in SH (Fig. $7 f-i$ ), thus clearly indicating the beneficial effect of EE during pregnancy.
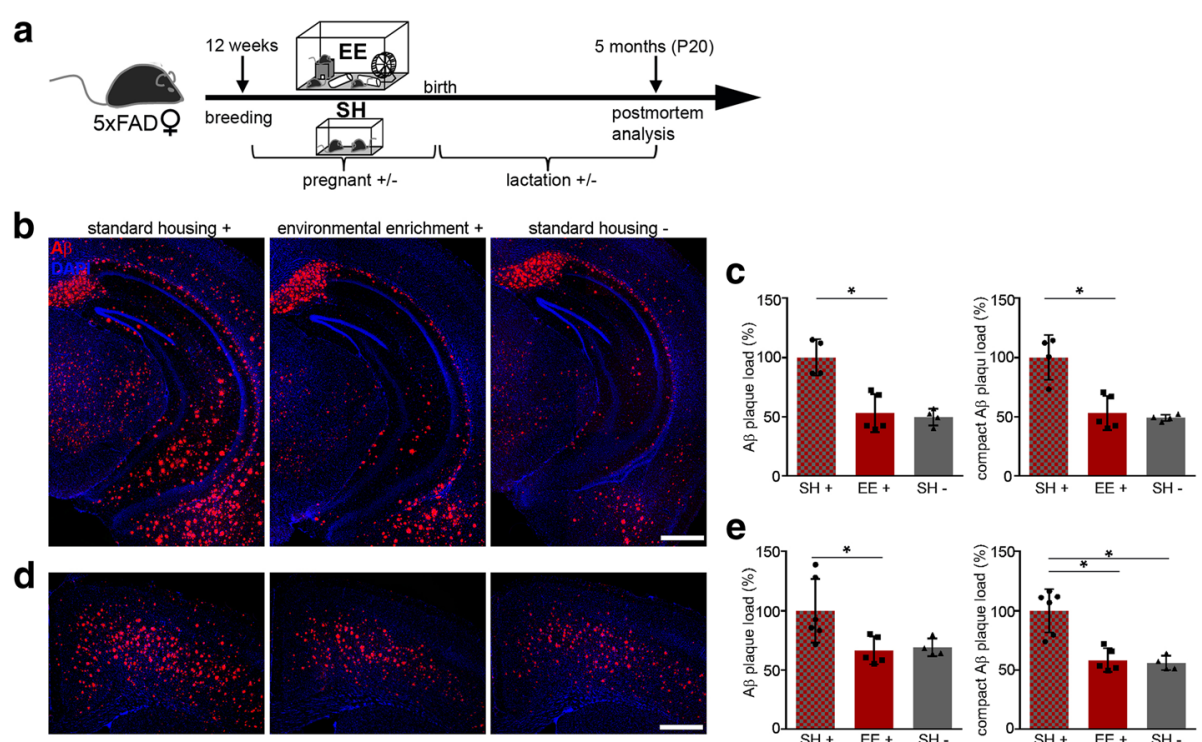

e
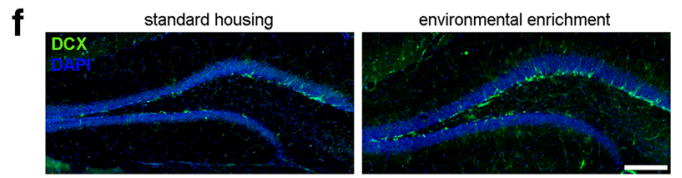

h
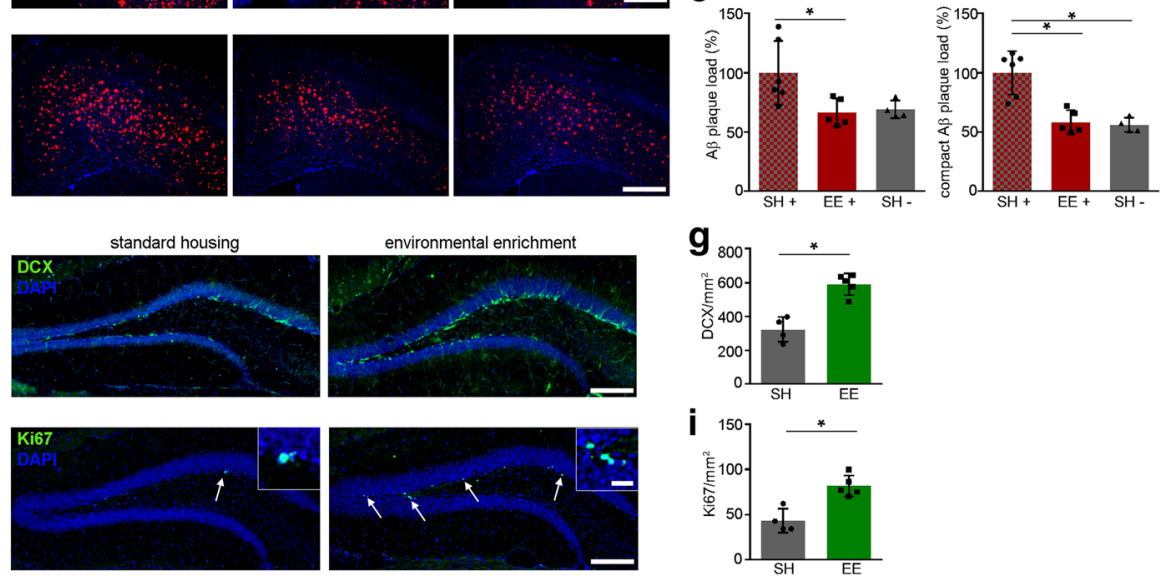

Fig. 7 Environmental enrichment during pregnancy and lactation rescues $A \beta$ plaque pathology in $5 x F A D$ mice. a Schematic overview of the experimental setup. Twelve weeks old 5xFAD female mice were mated and either housed in standard housing (SH) or in environmental enrichment (EE) until they were sacrificed at postpartum day 20 (P20). b Fluorescence microscopy of AB (red) and DAPI (blue). Shown are representative images of hippocampi from pregnant/lactating female 5xFAD mice housed in SH or EE and non-pregnant females housed in SH. c Quantification of A $\beta$ plaque load (left) and compact A $\beta$ plaque load (right) of pregnant/lactating 5xFAD mice housed in SH or EE displayed significant decreases in the number of $A \beta$ plaques after housing in EE. Kruskal-Wallis test followed by Dunn's multiple comparison test, ${ }^{*} P=0.039$, ${ }^{*} P=0.03$. $\mathbf{d}$ Fluorescence microscopy of $A \beta$ (red) and DAPI (blue). Shown are representative images of the cortex from pregnant/lactating female 5xFAD mice at P20 housed in SH or EE and non-pregnant females housed in SH. e Quantification of A $\beta$ plaque load in the cortex of pregnant/ lactating 5xFAD mice at P20 exhibited significant decreases in mice housed in EE. Kruskal-Wallis test followed by Dunn's multiple comparison test, ${ }^{*} P=0.024,{ }^{*} P=0.017$. f Fluorescence microscopy of DCX (green) and DAPI (blue). Shown are representative images of the dentate gyrus from pregnant 5xFAD female mice housed in SH or EE sacrificed at P20. g Quantification of DCX positive cells in pregnant/lactating 5xFAD mice showed significant increases in mice housed in EE. Mann-Whitney test, ${ }^{*} P=0.015$. $\mathbf{h}$ Fluorescence microscopy of Ki67 (green) and DAPI (blue). Shown are representative images of the dentate gyrus from pregnant female 5xFAD mice housed in SH or EE. i Analysis of Ki67 positive cells in pregnant/lactating 5xFAD mice revealed significant increases in mice housed in EE. Mann-Whitney test, ${ }^{*} P=0.015$. Inserts show higher magnifications. White arrows indicate Ki67 positive cells. Scale bar represents $500 \mu \mathrm{m}$ in (b and $\mathbf{d})$ and $100 \mu \mathrm{m}$ in (f and $\mathbf{h})$ and $20 \mu \mathrm{m}$ in the insert. Data are presented as mean \pm S.D. Each symbol represents data from one mouse, with four to six mice per group. SH = standard housing, $\mathrm{EE}=$ environmental enrichment, $\mathrm{DCX}=$ doublecortin, $\mathrm{P}=$ postpartum day 


\section{Discussion}

Age and gender are the greatest non-genetic risk factors for developing sporadic AD. There are indications that reproductive experiences are the cause for an earlier onset of AD in women. However, only few studies have investigated the underlying mechanism for the higher risk of $\mathrm{AD}$ in women $[6,7,31,33]$. Furthermore, the impact of pregnancy on $A \beta$ plaque pathology and adult neurogenesis still remains elusive. To this end, we analyzed pregnant 5xFAD transgenic mice at different gestation days by immunohistochemical stainings and determined the $A \beta$ plaque load as well as proliferation and neurogenesis. Indeed we found that pregnancy alters $A \beta$ plaque pathology in female $5 x F A D$ mice and reduces cell proliferation and the generation of newborn neurons in the hippocampus. Considering that female 5xFAD transgenic mice that also nursed their offspring for 4 weeks had a similar A $\beta$ plaque load and Ki67- and DCX cell counts as merely pregnant mice, we conclude that pregnancy alone is sufficient to exacerbate this pathology.

Epidemiological studies reported that women with multiple pregnancies have an earlier onset of $\mathrm{AD}$ and that nulliparous women show less age-related cognitive decline $[6,7,25,31]$. Our data do not support this view since we could not detect any difference in $A \beta$ plaque load between nulliparous and multiparous 5xFAD female mice, suggesting no higher risk for multiparous female mice. However, we can't exclude the possibility that a significant difference would have been detectable in a slower A $\beta$ aggregation mouse model such as APP23 or Tg2576 with an overall lower A $\beta$ plaque burden at that age. Future studies will need to address this question. In further support of a mechanistic link between pregnancy, motherhood and an increased risk for the development of $\mathrm{AD}$, it is observed that nulliparous women have higher estrogen levels later in life compared to women with reproductive experiences [2, 23]. Nevertheless, it is still under debate if estrogens could also have protective functions and eventually delay the onset of AD [11, 24, 28]. However, most findings in human studies should be taken cautiously because they contain insufficient information on the usage of birth control pills, especially in nulliparous women. While our results demonstrate a substantial increase in $A \beta$ plaque formation during the course of pregnancy in 5xFAD transgenic mice compared to non-pregnant littermates, they also suggest that progesterone rather than estrogen levels might account for this result since estrogen levels were similar in pregnant WT and 5xFAD transgenic mice. The question whether estrogen levels change during aging in 5xFAD transgenic mice still remains open. This could give additional interesting hints specifically in comparison to the situation in humans. Recent work in rats has demonstrated that pregnancy-related hormones might also play a role in $A \beta$ clearance by influencing $A \beta$ clearance factors such as IDE [17]. In agreement with the proposed relationship between levels of pregnancy-related hormones and IDE [17], we indeed found higher IDE levels in pregnant than in non-pregnant 5xFAD mice that also had high progesterone levels. It still remains an open question why pregnant 5xFAD mice had increased $A \beta$ levels despite elevated IDE levels that most likely were not able to execute its $A \beta$-degrading function. In contrast, neprilysin levels were not altered. Together, these experiments suggest that both, IDE and neprilysin did not affect the clearance of $A \beta$ in a way that could account for the increased plaque density in pregnant mice. Instead, the high amount of CTF- $\beta$ in pregnant mice might rather indicate that the observed increase in amyloid plaque density was primarily due to alterations in APP processing and A $\beta$ production.

Given that lactation might also affect pathology, we further included non-lactating and lactating 5xFAD mice in our study, in order to determine if lactation could enlarge pathological changes during the postpartum period. In agreement with other studies we were able to confirm that breeders display higher numbers of $A \beta$ plaques compared to non-breeders [8]. Importantly, this finding was applicable to other brain regions, such as the cortex and the olfactory bulb. Interestingly, there was no difference in $A \beta$ plaque pathology between $5 x F A D$ mice that nursed their offspring and those separated from the offspring directly after birth. Therefore we concluded that pregnancy alone is sufficient to induce this phenotype.

Reproductive experience, pregnancy and lactation influence physiological and endocrinological systems in women [4, 30, 32, 36]. Reproductive hormones that are produced during pregnancy and the postpartum period are known to alter neurogenesis and dendritic morphology [30, 32]. Cognitive deficits after reproductive experiences have been reported in human as well as in mouse studies [8, 12], although with inconclusive and contradictory results. While Cui et al [8] were able to show that WT breeders outperformed non-breeders in spatial working and memory they found the opposite in APP transgenic mice. Several studies provided evidence for the involvement of hippocampal neurogenesis in learning and memory and for its alteration under disease conditions such as $\mathrm{AD}$ and during reproductive experiences $[10,15,20,21]$. To establish whether adult hippocampal neurogenesis is altered during the course of pregnancy and in the postpartum period, we carried out a detailed analysis and quantified Ki67 and DCX-positive cells. Indeed, adult hippocampal neurogenesis and cell proliferation were significantly diminished in 5 month old pregnant and lactating $5 x F A D$ mice, suggesting that in the course of pregnancy the generation and maturation of 
newborn neurons is disturbed. Again, the lactation period alone had no influence on cell proliferation and adult neurogenesis. In summary, our data is in support of several human studies claiming that pregnancy is a risk factor for $\mathrm{AD}$.

Previous work has demonstrated that voluntary running and EE can have beneficial effects on $A \beta$ plaque formation and adult hippocampal neurogenesis $[16,18,19,22,26,37,38,41]$. While there is no data published regarding the impact of voluntary running and EE on pregnant and lactating mothers, it has been reported that running during pregnancy reduces the $A \beta$ plaque burden in transgenic offspring [13]. Inspired by a study that reports high running activity of pregnant mice until gestation day 10 [3], we exposed pregnant mice to an EE and investigated $A \beta$ plaque pathology and adult neurogenesis during pregnancy and in the postpartum period. Intriguingly, maternal voluntary running and exercise prevented the pregnancy related increase in $A \beta$ plaque pathology and stimulated cell proliferation as well as the generation of newborn neurons during the course of pregnancy. This beneficial effect of EE during the course of pregnancy was even more pronounced after the lactation period at P20, suggesting stronger effects with longterm EE. It remains to be seen if housing the pregnant mice in EE provides protection early on e.g. already at G10. Future experiments will have to test whether maternal voluntary running and exercise have long lasting effects on $A \beta$ plaque pathology and adult neurogenesis as suggested by others [3] and whether maternal activity might lead to changes in hormone levels, such as estrogens or progesterone.

\section{Conclusion}

In conclusion, the present study demonstrates that $A \beta$ plaque formation, cell proliferation and adult neurogenesis are dynamic processes, which can be influenced by reproductive activity on the one hand and physical exercise on the other hand. Together, our findings are unique and underscore the vulnerability of female brains during pregnancy and the effectiveness of EE as a non-pharmacological approach to counteract this happening.

\section{Acknowledgements}

We are grateful to J. Zbiegly for technical assistance and S. Kemna and M. Hüll for excellent comments on the manuscript. We also would like to thank E. Kremmer (Ludwig-Maximilians University, Munich) for the $A \beta$ antibodies (3552 and 6687)

\section{Funding}

This work was supported by the Deutsche Forschungsgemeinschaft (DFG) ME 3542/2-1 (M.M-L.), the Hans and Ilse Breuer Foundation (M.M-L.) and the NeuroMać Graduate School of the SFB/TRR 167 (M.F.).

\section{Availability of data and materials}

The datasets supporting the conclusions of this article are included within the article.

\section{Authors' contributions}

$\mathrm{SZ}-\mathrm{W}, \mathrm{KM}, \mathrm{JS}, \mathrm{PdE}, \mathrm{MF}, \mathrm{DE}, \mathrm{LN}, \mathrm{VS}, \mathrm{IO}$ and MD performed the experimental work. SZ-W and MM-L conceived and designed the experiments. SZ-W contributed to all aspects of the experimental work and data analysis. SZ-W, $M P$ and MM-L discussed the results. SZ-W and MM-L wrote the manuscript; $M M-L$ supervised the project. All authors edited the paper. All authors read and approved the final manuscript.

\section{Ethics approval}

All animal studies were reviewed, approved and carried out in accordance with the policies of the state of Baden-Württemberg under license number $\mathrm{X} 14 / 02 \mathrm{~A}$ and $\mathrm{X} 17 / 01 \mathrm{~A}$

\section{Competing interests}

The authors declare that they have no competing interests.

\section{Publisher's Note}

Springer Nature remains neutral with regard to jurisdictional claims in published maps and institutional affiliations.

\section{Author details}

${ }^{1}$ Department of Neurology, Medical Center - University of Freiburg, Freiburg, Germany. ${ }^{2}$ Faculty of Medicine, University of Freiburg, Freiburg, Germany. ${ }^{3}$ Faculty of Biology, University of Freiburg, Freiburg, Germany. ${ }^{4}$ Institute of Neuropathology, Medical Center - University of Freiburg, Freiburg, Germany. ${ }^{5} \mathrm{BIOSS}$ Centre for Biological Signalling Studies, University of Freiburg, Freiburg, Germany. ${ }^{6}$ Neurocenter, University of Freiburg, Breisacher Str.64, 79106 Freiburg, Germany.

Received: 2 May 2018 Accepted: 20 May 2018

Published online: 31 May 2018

\section{References}

1. Bayer TA, Schafer S, Simons A, Kemmling A, Kamer T, Tepest R, Eckert A, Schussel K, Eikenberg O, Sturchler-Pierrat C et al (2003) Dietary cu stabilizes brain superoxide dismutase 1 activity and reduces amyloid Abeta production in APP23 transgenic mice. Proc Natl Acad Sci U S A 100:14187-14192

2. Bernstein L, Pike MC, Ross RK, Judd HL, Brown JB, Henderson BE (1985) Estrogen and sex hormone-binding globulin levels in nulliparous and parous women. J Natl Cancer Inst 74:741-745

3. Bick-Sander A, Steiner B, Wolf SA, Babu H, Kempermann G (2006) Running in pregnancy transiently increases postnatal hippocampal neurogenesis in the offspring. Proc Natl Acad Sci U S A 103:3852-3857

4. Bridges RS (2016) Long-term alterations in neural and endocrine processes induced by motherhood in mammals. Horm Behav 77:193-203

5. Callahan MJ, Lipinski WJ, Bian F, Durham RA, Pack A, Walker LC (2001) Augmented senile plaque load in aged female beta-amyloid precursor protein-transgenic mice. Am J Pathol 158:1173-1177

6. Colucci M, Cammarata S, Assini A, Croce R, Clerici F, Novello C, Mazzella L, Dagnino N, Mariani C, Tanganelli P (2006) The number of pregnancies is a risk factor for Alzheimer's disease. Eur J Neurol 13:1374-1377

7. Corbo RM, Gambina G, Ulizzi L, Monini P, Broggio E, Rosano A, Scacchi R (2007) Combined effect of apolipoprotein e genotype and past fertility on age at onset of Alzheimer's disease in women. Dement Geriatr Cogn Disord 24:82-85

8. Cui J, Jothishankar B, He P, Staufenbiel M, Shen Y, Li R (2014) Amyloid precursor protein mutation disrupts reproductive experience-enhanced normal cognitive development in a mouse model of Alzheimer's disease. Mol Neurobiol 49:103-112

9. Cummings JL (2004) Alzheimer's disease. N Engl J Med 351:56-67

10. Ekonomou A, Savva GM, Brayne C, Forster G, Francis PT, Johnson M, Perry EK, Attems J, Somani A, Minger SL et al (2015) Stage-specific changes in neurogenic and glial markers in Alzheimer's disease. Biol Psychiatry 77:711-719

11. Henderson WW, Paganini-Hill A, Emanuel CK, Dunn ME, Buckwalter JG (1994) Estrogen replacement therapy in older women. Comparisons between Alzheimer's disease cases and nondemented control subjects. Arch Neurol 51:896-900 
12. Henry JF, Sherwin BB (2012) Hormones and cognitive functioning during late pregnancy and postpartum: a longitudinal study. Behav Neurosci 126: 73-85

13. Herring A, Donath A, Yarmolenko M, Uslar E, Conzen C, Kanakis D, Bosma C, Worm K, Paulus W, Keyvani K (2012) Exercise during pregnancy mitigates Alzheimer-like pathology in mouse offspring. FASEB J 26:117-128

14. Hirata-Fukae C, Li HF, Hoe HS, Gray AJ, Minami SS, Hamada K, Niikura T, Hua F, Tsukagoshi-Nagai H, Horikoshi-Sakuraba Y et al (2008) Females exhibit more extensive amyloid, but not tau, pathology in an Alzheimer transgenic model. Brain Res 1216:92-103

15. Hollands C, Bartolotti N, Lazarov O (2016) Alzheimer's disease and hippocampal adult neurogenesis; exploring shared mechanisms. Front Neurosci 10:178

16. Hu YS, Xu P, Pigino G, Brady ST, Larson J, Lazarov O (2010) Complex environment experience rescues impaired neurogenesis, enhances synaptic plasticity, and attenuates neuropathology in familial Alzheimer's diseaselinked APPswe/PS1DeltaE9 mice. FASEB J 24:1667-1681

17. Jayaraman A, Carroll JC, Morgan TE, Lin S, Zhao L, Arimoto JM, Murphy MP, Beckett TL, Finch CE, Brinton RD et al (2012) 17beta-estradiol and progesterone regulate expression of beta-amyloid clearance factors in primary neuron cultures and female rat brain. Endocrinology 153:5467-5479

18. Kempermann G, Kuhn HG, Gage FH (1997) More hippocampal neurons in adult mice living in an enriched environment. Nature 386:493-495

19. Kempermann G, Kuhn HG, Gage FH (1998) Experience-induced neurogenesis in the senescent dentate gyrus. J Neurosci 18:3206-3212

20. Lazarov O, Marr RA (2010) Neurogenesis and Alzheimer's disease: at the crossroads. Exp Neurol 223:267-281

21. Lazarov O, Mattson MP, Peterson DA, Pimplikar SW, van Praag H (2010) When neurogenesis encounters aging and disease. Trends Neurosci 33: 569-579

22. Lazarov O, Robinson J, Tang YP, Hairston IS, Korade-Mirnics Z, Lee VM, Hersh LB, Sapolsky RM, Mirnics K, Sisodia SS (2005) Environmental enrichment reduces Abeta levels and amyloid deposition in transgenic mice. Cell 120: 701-713

23. Lee JH, Jiang Y, Han DH, Shin SK, Choi WH, Lee MJ (2014) Targeting estrogen receptors for the treatment of Alzheimer's disease. Mol Neurobiol 49:39-49

24. Liang K, Yang L, Yin C, Xiao Z, Zhang J, Liu Y, Huang J (2010) Estrogen stimulates degradation of beta-amyloid peptide by up-regulating neprilysin. J Biol Chem 285:935-942

25. McLay RN, Maki PM, Lyketsos CG (2003) Nulliparity and late menopause are associated with decreased cognitive decline. J Neuropsychiatry Clin Neurosci 15:161-167

26. Nilsson M, Perfilieva E, Johansson U, Orwar O, Eriksson PS (1999) Enriched environment increases neurogenesis in the adult rat dentate gyrus and improves spatial memory. J Neurobiol 39:569-578

27. Oakley H, Cole SL, Logan S, Maus E, Shao P, Craft J, Guillozet-Bongaarts A, Ohno M, Disterhoft J, Van Eldik L et al (2006) Intraneuronal beta-amyloid aggregates, neurodegeneration, and neuron loss in transgenic mice with five familial Alzheimer's disease mutations: potential factors in amyloid plaque formation. J Neurosci 26:10129-10140

28. Paganini-Hill A, Henderson WW (1994) Estrogen deficiency and risk of Alzheimer's disease in women. Am J Epidemiol 140:256-261

29. Paxinos G, Franklin KBJ (2001) The mouse brain in stereotaxic coordinates 2n edn. San Diego, Academic Press

30. Prange-Kiel J, Rune GM (2006) Direct and indirect effects of estrogen on rat hippocampus. Neuroscience 138:765-772

31. Ptok U, Barkow K, Heun R (2002) Fertility and number of children in patients with Alzheimer's disease. Arch Womens Ment Health 5:83-86

32. Shingo T, Gregg C, Enwere E, Fujikawa H, Hassam R, Geary C, Cross JC, Weiss S (2003) Pregnancy-stimulated neurogenesis in the adult female forebrain mediated by prolactin. Science 299:117-120

33. Sobow T, Kloszewska I (2004) Parity, number of pregnancies, and the age of onset of Alzheimer's disease. J Neuropsychiatry Clin Neurosci. 16:120-121

34. Steiner H, Kostka M, Romig H, Basset G, Pesold B, Hardy J, Capell A, Meyn L, Grim ML, Baumeister R et al (2000) Glycine 384 is required for presenilin-1 function and is conserved in bacterial polytopic aspartyl proteases. Nat Cell Biol 2:848-851

35. Sturchler-Pierrat C, Staufenbiel M (2000) Pathogenic mechanisms of Alzheimer's disease analyzed in the APP23 transgenic mouse model. Ann N Y Acad Sci 920:134-139
36. Tomizawa K, Iga N, Lu YF, Moriwaki A, Matsushita M, Li ST, Miyamoto O, Itano T, Matsui H (2003) Oxytocin improves long-lasting spatial memory during motherhood through MAP kinase cascade. Nat Neurosci 6:384-390

37. van Praag H, Christie BR, Sejnowski TJ, Gage FH (1999a) Running enhances neurogenesis, learning, and long-term potentiation in mice. Proc Natl Acad Sci U S A 96:13427-13431

38. van Praag H, Kempermann G, Gage FH (1999b) Running increases cell proliferation and neurogenesis in the adult mouse dentate gyrus. Nat Neurosci 2:266-270

39. Wang J, Tanila H, Puolivali J, Kadish I, van Groen T (2003) Gender differences in the amount and deposition of amyloidbeta in APPswe and PS1 double transgenic mice. Neurobiol Dis 14:318-327

40. Yamasaki A, Eimer S, Okochi M, Smialowska A, Kaether C, Baumeister R, Haass C, Steiner H (2006) The GxGD motif of presenilin contributes to catalytic function and substrate identification of gamma-secretase. J Neurosci 26:3821-3828

41. Ziegler-Waldkirch S, d'Errico P, Sauer JF, Erny D, Savanthrapadian S, Loreth D, Katzmarski N, Blank T, Bartos M, Prinz M et al (2018) Seed-induced Abeta deposition is modulated by microglia under environmental enrichment in a mouse model of Alzheimer's disease. EMBO J 37:167-182

\section{Ready to submit your research? Choose BMC and benefit from:}

- fast, convenient online submission

- thorough peer review by experienced researchers in your field

- rapid publication on acceptance

- support for research data, including large and complex data types

- gold Open Access which fosters wider collaboration and increased citations

- maximum visibility for your research: over $100 \mathrm{M}$ website views per year

At BMC, research is always in progress.

Learn more biomedcentral.com/submissions 